\title{
Long-term results of Gamma Knife surgery for uveal melanomas
}

\author{
Clinical article
}

\author{
Dong Wan Kang, M.D., ${ }^{1}$ Sung Chul Lee, M.D., Ph.D., ${ }^{2}$ Yong Gou Park, M.D., Ph.D., ${ }^{3-5}$ \\ and Jong Hee Chang, M.D., Ph.D. ${ }^{3-5}$ \\ ${ }^{1}$ Department of Neurosurgery, Pusan National University School of Medicine, Busan, Korea; and \\ Departments of ${ }^{2}$ Ophthalmology and ${ }^{3}$ Neurosurgery, ${ }^{4}$ Gamma Knife Center, and ${ }^{5}$ Brain Research Institute, \\ Yonsei University College of Medicine, Seoul, Korea
}

\begin{abstract}
Object. Gamma Knife surgery (GKS) is currently believed to be a safe and minimally invasive modality in the treatment of uveal melanomas. It could be used as an alternative treatment to enucleation, preserving the eyeball as well as visual function. The authors report their experiences with GKS for uveal melanomas for the period from February 1998 to December 2006.

Methods. Twenty-two patients with uveal melanoma were enrolled in this study. The population consisted of 12 men and 10 women with a mean age of 53.4 years (range 24-79 years). The mean tumor volume was $877 \mathrm{~mm}^{3}$, and the mean margin dose was $45.6 \mathrm{~Gy}$. The median follow-up period was 67 months (range 3-126 months). All of the patients had received a diagnosis and referral from an ophthalmology clinic; the patients underwent a preoperative orbital examination that included MRI.

Results. Tumor regression was achieved in 20 patients $(90.9 \%)$, whereas tumor progression was observed in 2 patients $(9.1 \%) 3$ years after GKS. The cumulative 1-year and 2-year mean rates of tumor thickness reduction were $18.8 \%$ and $42.8 \%$, respectively. The mean rate of tumor volume reduction was $63.7 \%$. The rate of eye retention 5 years after radiosurgery was $77.3 \%$ (17 of 22 patients). Overall visual acuity was reduced after GKS in all patients; 14 patients $(63.6 \%)$ displayed preserved visual function better than hand-movement perception. The most frequent side effect was cataract, which was detected in 9 patients (40.9\%); this was followed in frequency by radiation-induced retinopathy in 5 patients $(22.7 \%)$.

Conclusions. Gamma Knife surgery provides excellent local control of uveal melanomas with a decrease in volume over time. This procedure not only preserves the eyeball and its potential visual function, but also decreases the potential for hematological dissemination and achieves sufficient local tumor control with a gradual reduction in volume.
\end{abstract}

(http://thejns.org/doi/abs/10.3171/2012.8.GKS121002)

KeY Words • uveal melanoma • Gamma Knife • stereotactic radiosurgery

$\mathrm{U}$ VEAL melanoma is the most common form of primary intraocular malignancy in adults, with an incidence of 0.61 per 100,000 person-years in whites and 0.05 per 100,000 person-years in AfricanAmericans. ${ }^{14,25}$ Several therapeutic options are available, including resection or enucleation, brachytherapy, and stereotactic irradiation. Despite the range of treatment modalities, the prognosis of this disease still remains discouraging. Whereas traditionally, enucleation has long been the traditional treatment of uveal melanomas, GKS is now believed to be a safe and minimally invasive treatment modality for these lesions. Gamma Knife surgery can preserve the eyeball and visual acuity on one side,

Abbreviation used in this paper: GKS = Gamma Knife surgery. even if it is impossible to preserve it on the other side. The purpose of the present study was to describe our treatment protocol and evaluate the results of GKS in 22 patients treated for uveal melanoma between February 1998 and December 2006.

\section{Methods}

\section{Patient Characteristics}

We retrospectively reviewed the medical records of 22 patients with uveal melanoma who consecutively underwent GKS between February 1998 and December 2006. The patient population was composed of 12 men and 10 women ranging in age from 24 to 79 years (mean age 53.4 years). The mean tumor volume in these patients was $877 \mathrm{~mm}^{3}$ (range $101.1-5828.6 \mathrm{~mm}^{3}$ ), and preopera- 
tive visual acuity, determined using the Snellen chart, was between 0.05 and 1.2. The median follow-up period in this population was 67 months (range 3-126 months). The locations of the tumors included anterior to the equator in 8 patients, posterior to the equator in 8 patients, and on both sides of the equator or throughout the whole eye in 6 patients (Table 1 ).

The diagnosis of uveal melanoma was based on pathological confirmation of the lesion through incisional biopsy in 10 patients (45.5\%). In 12 patients the diagnosis was based on imaging and fundoscopic findings without biopsy. All patients had received their diagnosis and referral from ophthalmology clinics, and all had undergone an orbital examination preoperatively. Before GKS, we measured the tumor thickness and the approximate tumor volume.

All patients were examined by an ophthalmologist regularly after GKS, and MRI examinations were performed at regular intervals. Local disease control was defined as freedom from tumor progression and was measured using MRI. The imaging protocol for the treatment plan specified Gd-enhanced MRI using the fat suppression technique as the preferred method. Gadolinium enhancement enables delineation of the tumor from subretinal fluid, hemorrhage, retinal detachment, and choroidal hemangioma. In MRI, the border of the tumor shows a hyperintensity compared to vitreous humor on Gd-enhanced T1-weighted images; on T2-weighted images it displays a slight hypointensity.

\section{Surgical Fixation of the Eye}

For successful radiosurgery for uveal melanomas, complete immobilization of the eyeball is considered very important. This can be achieved by a retrobulbar injection of $2 \%$ xylocaine followed by transconjunctival fixation of the four rectus muscles using 5-0 silk. Following this, conjunctival flaps are sutured to the upper or lower eyelid and then ophthalmic ointment is applied to the opened eye (Fig. 1).

\section{Treatment Planning}

Before September 1999, we used the KULA doseplanning program (initially version 5.4 and later upgraded) to treat patients; after that date, we used the GammaPlan system (version 5.30, Elekta AB). Before October 2004, we used Leksell Gamma Knife model B; thereafter, we used the model C (Elekta AB). After we had upgraded to model $\mathrm{C}$, we were able to use a larger number of small collimators, and it was easier to employ the plugging technique against vital structures. When treating a uveal melanoma, the aim is to surround the tumor with a high isodose. Isodoses in the range of 50\% to $97 \%$ were used to maximize the falloff of the radiation dose outside the target. The prescribed dose to the tumor margin ranged between 20 to $67.5 \mathrm{~Gy}$ and the mean dose was $45.6 \mathrm{~Gy}$. In 19 patients one isocenter was used, and in the other 3 patients two isocenters were used.

\section{Measurements of Tumor Volume and Temporal Changes in Volume}

Most of the uveal melanomas had an ellipsoid shape,
TABLE 1: Characteristics in 22 patients with malignant uveal melanomas

\begin{tabular}{lc}
\hline \multicolumn{1}{c}{ Characteristic } & Value \\
\hline sex-no. of patients (\%) & $12(54.5)$ \\
male & $10(45.5)$ \\
female & $53.4(24-79)$ \\
mean age in yrs (range) & $877(101.1-5828.6)$ \\
mean tumor vol in mm $^{3}$ (range) & \\
tumor location-no. of lesions (\%) & $8(36.4)$ \\
anterior to equator & $8(36.4)$ \\
posterior to equator & $6(27.3)$ \\
both sides of equator & \\
laterality-no. of lesions (\%) & $13(59.1)$ \\
rt & $9(40.9)$ \\
It & $45.6(20-67.5)$ \\
mean dose (Gy) directed at tumor margin & \\
(range) & $76.3(50-97)$ \\
\% isodose (range) & $67(3-126)$ \\
median follow-up in mos (range)
\end{tabular}

and we measured their volumes using the following formula: volume $=(4 / 3)(\pi a b c)$, where $a=1 / 2$ long axis, $b=1 / 2$ short axis, and $c=1 / 2$ height). This method had limitations in that it was difficult to measure the exact size of the tumor using MRI, and sometimes the tumor shape was not in the form of an ideal ellipsoid, making it difficult to calculate the exact tumor volume. However, we were able to calculate the approximate tumor volume as well as volume changes as time passed.

\section{Statistical Analysis}

To evaluate the complications and side effects following GKS, the development of secondary glaucoma, cataract, retinal detachment, and radiation-indiced retinopathy after GKS was studied as a function of the prescribed margin dose, tumor localization, and total volume of the prescribed isodose. To determine the statistical significance of these factors, the chi-square test or the Fisher exact test (when the expected value was $<5$ ) was used. The variable was considered significant when the probability value was less than 0.05 .

Four different variables were proposed as potential factors influencing regression of the tumor after irradiation of a uveal melanoma using GKS. These factors were patient sex and age, tumor volume, and prescribed margin dose.

Multivariate analyses were performed using the Cox proportional hazards model. Variables with significant probability values $(p<0.05)$ were considered possible factors affecting tumor regression, eye retention, or overall survival. Overall survival and eye retention after GKS were also analyzed using Kaplan-Meier statistics. All statistical analyses in this study were performed using the statistical software package SPSS (version 18, IBM). 


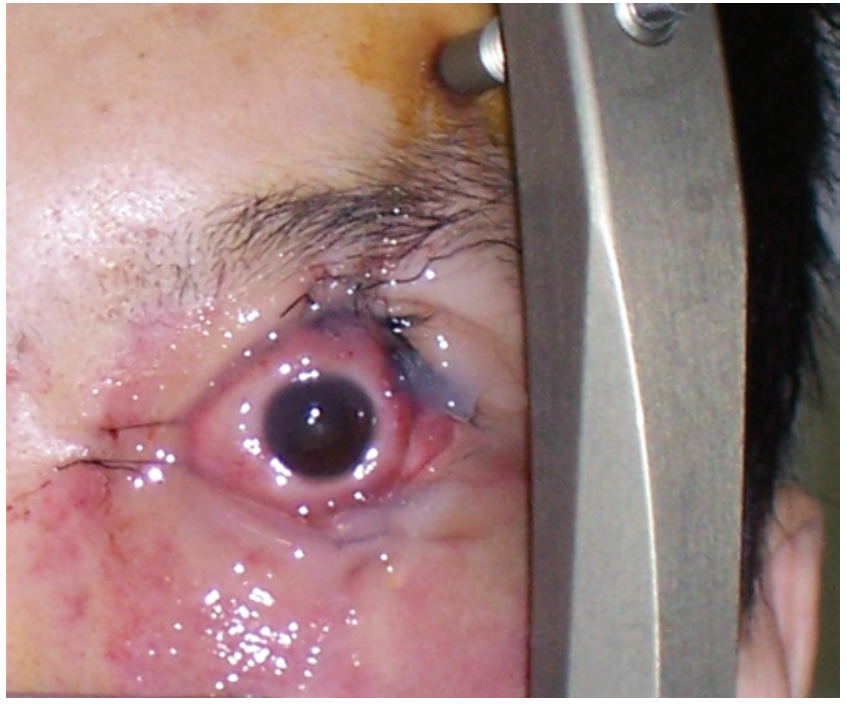

FIG. 1. Photograph showing the conjunctival flap suture after fixation of the rectus muscles.

\section{Results}

\section{Rate of Eye Retention}

Five treated eyes had to be enucleated because of tumor recurrence or treatment-related complications. Two patients had uncontrolled and enlarged melanomas; their eyes were enucleated 6 months after GKS. Two other patients suffered from severe retinal detachment and retinal hemorrhage; in one case the eye was enucleated 10 months post-GKS and in the other case 29 months after radiosurgery. In the fifth patient, the eye globe was enucleated 48 months after GKS because neovascularized glaucoma developed. In the whole group of patients, the eye retention rate was $86.4 \%$ ( 19 of 22 patients) 2 years after GKS and $77.3 \%$ (17 of 22 patients) 5 years after GKS (Fig. 2). The eye retention rate was analyzed according to patient age and sex, tumor volume, and tumor margin dose, but this failed to prove any statistical relationship among variables $(\mathrm{p}>0.05)$.

\section{Local Tumor Control Rate and Changes in Tumor Volume}

A significant reduction in tumor volume was observed after GKS, but the volume increased in 2 patients. Thus, the overall local tumor control rate, defined as stable or reduced tumor thickness, was $90.9 \%$. The mean tumor thickness before GKS was $9.53 \mathrm{~mm}$ (range $5.1-15.0 \mathrm{~mm}$ ), and the cumulative 1-year and 2-year mean tumor-thickness reduction rates were $18.8 \%$ and $42.8 \%$, respectively. We measured changes in tumor volume using the formula for the calculation of ellipsoid volume. The cumulative 1 -year mean volume reduction rate was $41.8 \%$ (range $4.1 \%-100 \%$ ) in the 20 patients in whom there was local tumor control. In the final follow-up, the mean volume reduction rate was $63.7 \%$ (Fig. 3). The melanomas disappeared almost completely in 5 patients, and the mean complete remission period was 5.2 months after GKS. A case in which tumor regression recurred 13 months after GKS is illustrated in Fig. 4. Unfortunately, 2 patients'

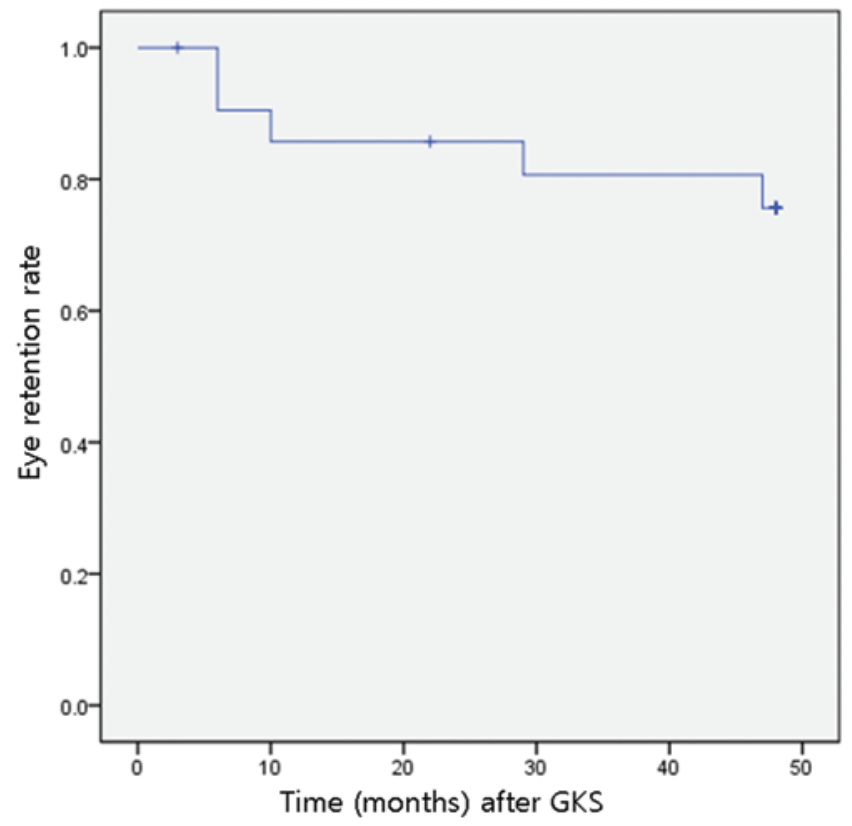

Fıg. 2. Kaplan-Meier cumulative curves for overall eye retention in 22 patients.

eyeballs were enucleated because of uncontrolled uveal melanomas.

\section{Overall Survival}

The overall 5-year survival rate was 90.9\% (20 of 22 patients) in our study. One patient died of causes related to liver metastasis from the uveal melanoma 4 months after GKS, and another patient died of lung cancer unrelated to the melanoma 22 months after radiosurgery. We analyzed patient survival according to age, sex, tumor volume, and margin dose; however, no relationship was found among these variables $(p>0.05)$ (Table 2$)$.

\section{Visual Acuity}

A significant reduction in visual acuity was observed. Before GKS, visual acuity, determined using the Snellen chart, ranged from light perception to 1.2 (median 0.6). After treatment, visual acuity ranged from blindness to 0.9 . Even though overall visual acuity was reduced after GKS in 21 of 22 patients, 14 patients (63.6\%) exhibited preserved visual function better than hand-movement perception, which could be considered an advantage of radiosurgery. Only 1 patient who had recognized light before GKS became blind after the procedure. One patient displayed a slight improvement in vision, from 0.6 to 0.9 during 6 years after radiosurgery.

\section{Other Side Effects After Gamma Knife Surgery}

Radiation-related side effects were evaluated ophthalmologically and on imaging studies at regular intervals by ophthalmologists and neurosurgeons. Subsequent ocular complications occurred in 18 of 22 patients. The most frequent side effect was cataract in 9 (40.9\%) of 22 patients, which was easily managed by ophthalmologists. 


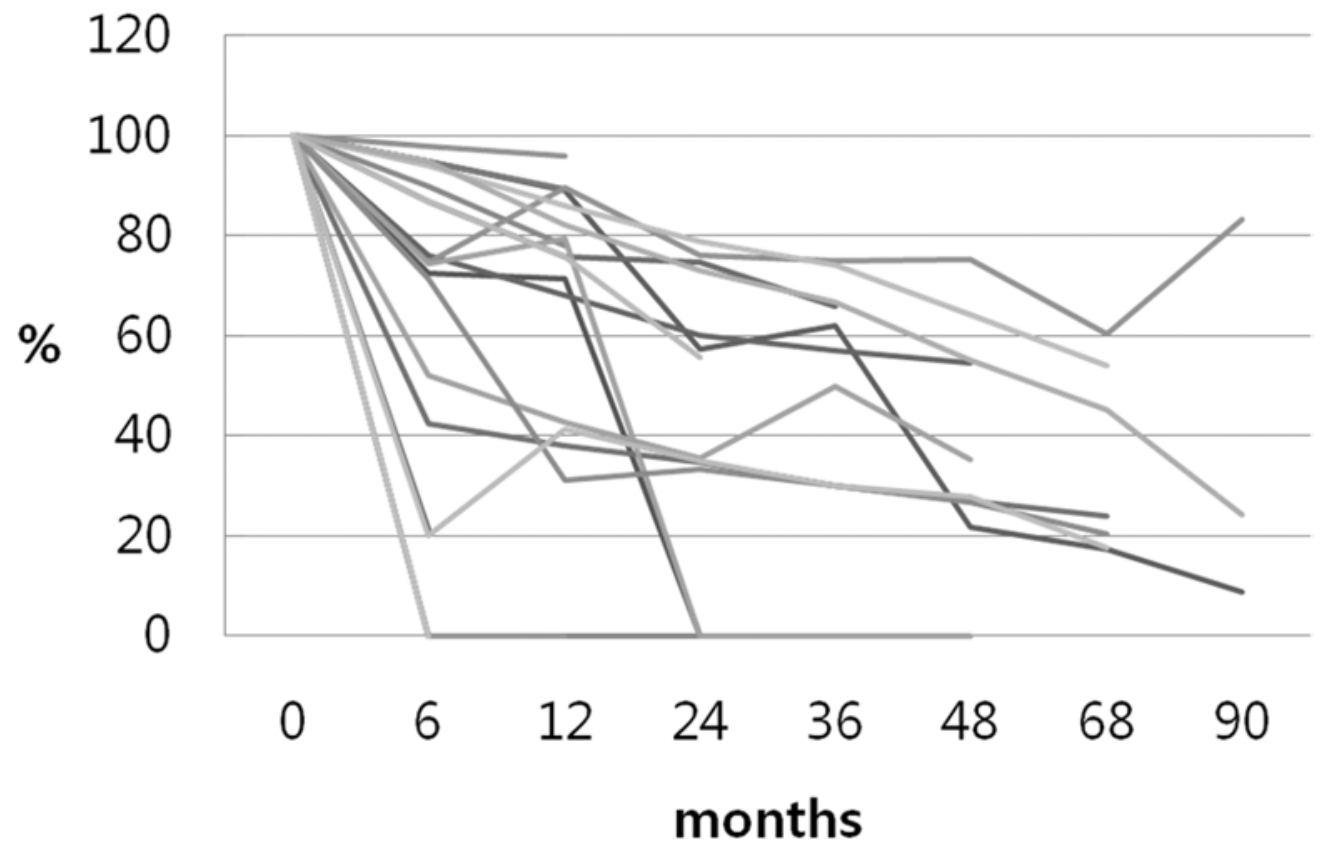

FIG. 3. Tumor volume changes during the follow-up in 20 patients. (Two cases whose volume had increased were excluded.)

Other complications included radiation-related retinopathy (5 cases), retinal detachment (2 cases), glaucoma (2 cases), and vitreous hemorrhage (2 cases). Some patients suffered from 2 or more concurrent complications. We could not find any significant relationship among any of

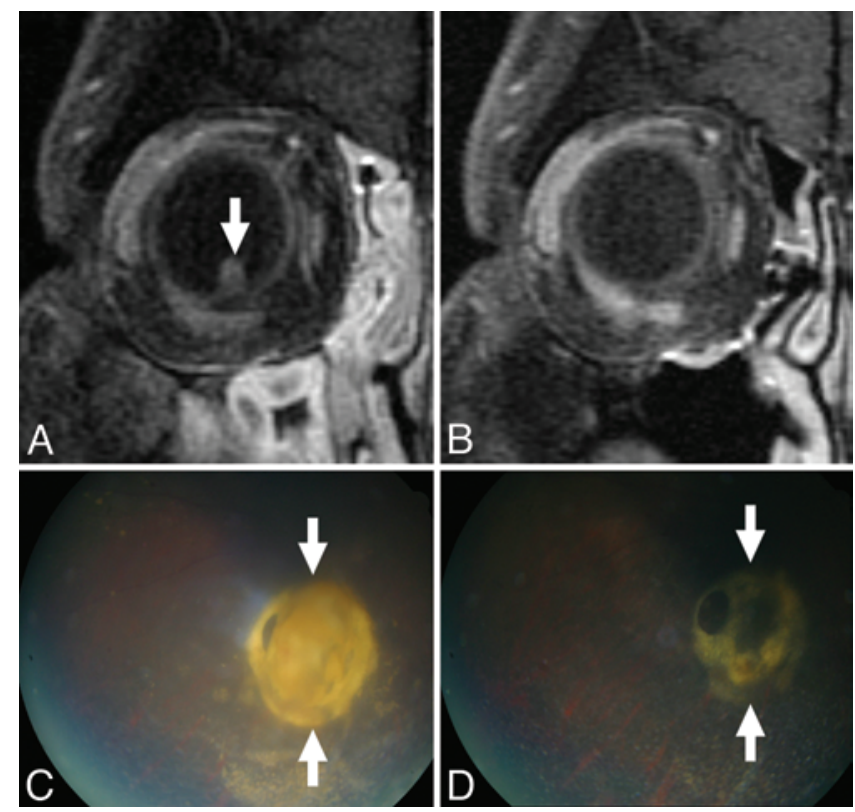

FIG. 4. A: Coronal contrast-enhanced T1-weighted MR image revealing a uveal melanoma situated at the inferior wall of the orbit before GKS (single arrow). B: Contrast-enhanced MR image obtained 13 months after GKS, showing nearly complete regression of the tumor. C: Fundoscopic views revealing an elevated yellowish subretinal mass (double arrows). D: Thirteen months after GKS a residual flat scar can be observed in the same area as the previous mass (double arrows). the side effects and several factors studied, such as radiation dose, tumor location, and tumor volume ( $\mathrm{p}>0.05)$.

\section{Discussion}

The selection of treatment for uveal melanomas is made in accordance with the general health status of the patient along with local findings related to the tumor, such as its stage and character; nevertheless, the disease is still considered difficult to treat. ${ }^{10}$ Various treatment modalities for uveal melanoma have been described in the literature. In recent years, eye globe-sparing techniques have become more widespread, and these include photocoagulation, transpupillary thermotherapy, radiotherapy, local resection, chemotherapy, immunotherapy, and stereotactic radiosurgery. $2,5,6,12,22,23$

Besides the advantages of being less invasive and better tolerated by the patient, GKS can preserve the globe and restore visual function. In addition, it is a single-day treatment that can be completed within a few hours. On the other hand, GKS could deliver a dose to adjacent radiosensitive intraocular organs that is higher than they can tolerate, and it could potentially increase the chance of distant metastasis by not eliminating the melanoma itself. Previous retrospective series, in which the outcomes of GKS in the treatment of uveal melanoma were evaluated, have shown mixed results. ${ }^{4,7,15,16,19,21,24,28,29}$

Modorati et al. ${ }^{18}$ reported that the 3 -year probability of survival for uveal melanoma after GKS was $88.8 \%$ and the 5-year probability of survival was $81.9 \%$. Fakiris et al. ${ }^{9}$ showed that the 3-and 5-year overall survival rates were $86 \%$ and $55 \%$, respectively. These 3 - and 5-year cumulative survival rates are comparable to those reported by others in cases of melanomas treated with GKS. 15,19,23,28,29 
TABLE 2: Survival according to variables*

\begin{tabular}{|c|c|c|c|c|}
\hline Factor & Category & No. of Cases & 1-Yr Survival & 2-Yr Survival \\
\hline \multirow[t]{2}{*}{ age (yrs) } & $\leq 50$ & 11 & 11 & 10 \\
\hline & $>50$ & 11 & 10 & 10 \\
\hline \multirow[t]{2}{*}{ sex } & male & 12 & 11 & 10 \\
\hline & female & 10 & 10 & 10 \\
\hline \multirow[t]{3}{*}{ tumor location } & anterior to equator & 8 & 7 & 6 \\
\hline & posterior to equator & 8 & 8 & 8 \\
\hline & both sides of equator & 6 & 6 & 6 \\
\hline \multirow[t]{2}{*}{ dose at tumor margin (Gy) } & $\leq 45$ & 10 & 10 & 10 \\
\hline & $>45$ & 12 & 11 & 10 \\
\hline \multirow[t]{2}{*}{ tumor vol $\left(\mathrm{mm}^{3}\right)$} & $\leq 500$ & 9 & 8 & 7 \\
\hline & $>500$ & 13 & 13 & 13 \\
\hline \multirow[t]{2}{*}{ laterality } & $\mathrm{rt}$ & 13 & 12 & 12 \\
\hline & It & 9 & 9 & 8 \\
\hline total & & 22 & 21 & 20 \\
\hline
\end{tabular}

In our study, the overall 5-year survival rate was $90.9 \%$ (20 of 22 patients). One patient died 4 months after GKS of causes related to liver metastasis from the uveal melanoma; the cause of death in the other patient, who died 22 months after GKS, was lung cancer unrelated to the melanoma. If we only consider the patient whose death was associated with melanoma, the survival rate is raised to $95.5 \%$ (21 of 22 patients). Cumulative 5-year survival after primary enucleation was reported to range from $31.45 \%$ to $65.2 \%,{ }^{7,11}$ and Dinca et al. ${ }^{7}$ reported that no survival difference was observed between GKS and primary enucleation therapy. Also, no statistically significant differences were found in survival between patients treated by cobalt plaque therapy and those treated by enucleation. ${ }^{1}$ Margo et al. ${ }^{17}$ concluded that there was no difference in 5-year survival rates in patients with medium-sized choroidal melanoma who were treated by iodine- 125 brachytherapy or enucleation. There is still debate on the most effective modality for treating uveal melanomas. We believe that GKS would be a good method, given the good cosmetic result and quality of life that it provides the patient.

In a series of 81 patients in whom GKS was used in the treatment of uveal melanomas, Simonová et al. ${ }^{24}$ achieved an $84 \%$ local tumor control rate at 10 months after GKS by applying a minimum dose of 31.4 Gy. Similarly, Modorati and colleagues ${ }^{18}$ achieved $91 \%$ tumor control in a group of 78 patients treated by GKS with $30-50$ Gy of radiation at the tumor periphery. However, high complication rates were observed, including enucleation $(10.3 \%)$, retinal detachment $(33.3 \%)$, and glaucoma (18.7\%). In our study, local tumor control was achieved in $20(90.9 \%)$ of 22 patients, and the cumulative rates of tumor thickness regression were $18.8 \%$ in the 1st year and $42.8 \%$ in the 2 nd year after GKS. Simonová et al. ${ }^{24}$ reported that patient age, tumor location, dissemination of disease, and applied minimum dose were identified as having a significant influence on patient survival. In our study, we could not find any significant values among age, sex, tumor margin dose, and tumor volume affecting survival.

A wide range of radiation doses was used in published series of GKS for uveal melanomas. Higher doses were used in earlier series, but there has been a general trend toward dose deescalation. Langmann et al. ${ }^{15}$ showed that a reduction in the dose directed to the tumor periphery from 50 to 40 Gy had no effect on the local tumor control rate, and this could minimize subsequent side effects. Mueller et al. ${ }^{19}$ reported that current treatments were performed using 25 Gy at $50 \%$ isodose to the tumor margin. We used a tumor margin dose that ranged from 20.0 to $67.5 \mathrm{~Gy}$, and a mean dose $45.6 \mathrm{~Gy}$, which includes the higher doses we used at the beginning of this study period.

The eye is a very radiosensitive organ, and it is not surprising that GKS can cause radiation-induced complications. The radiation tolerance of the optic nerve has been well defined in other radiosurgical procedures. The tolerance dose of the optic nerve is in the range of 8 to 10 Gy. ${ }^{13,20}$ However, the limits of an acceptable radiation dose are not clear for other tissues such as the retina, sclera, and iris. Even though radiation-induced complications involving the lens could be easily treated, atrophy of the optic nerve, corneal ulcers, and secondary glaucoma could represent far more serious problems. ${ }^{24}$ In our series, ocular complications occurred in 18 of 22 patients. While the tumor control rate was similar to those of other series, the incidence of complications seems to be somewhat higher. These results may be related to the relatively higher tumor marginal dose. However, as shown in Table 3 , no significant difference was noted in the tumor control rate when the radiation dose was changed. It seems that it is more reasonable to prescribe a lower radiation dose than the mean radiation dose used in our study to reduce any possible complications.

The rate of enucleation has been reported to range from $6 \%$ at the 2 -year follow-up to $19 \%$ at 8 years af- 
Radiosurgery for uveal melanoma

TABLE 3: Literature review of uveal melanomas treated by GKS*

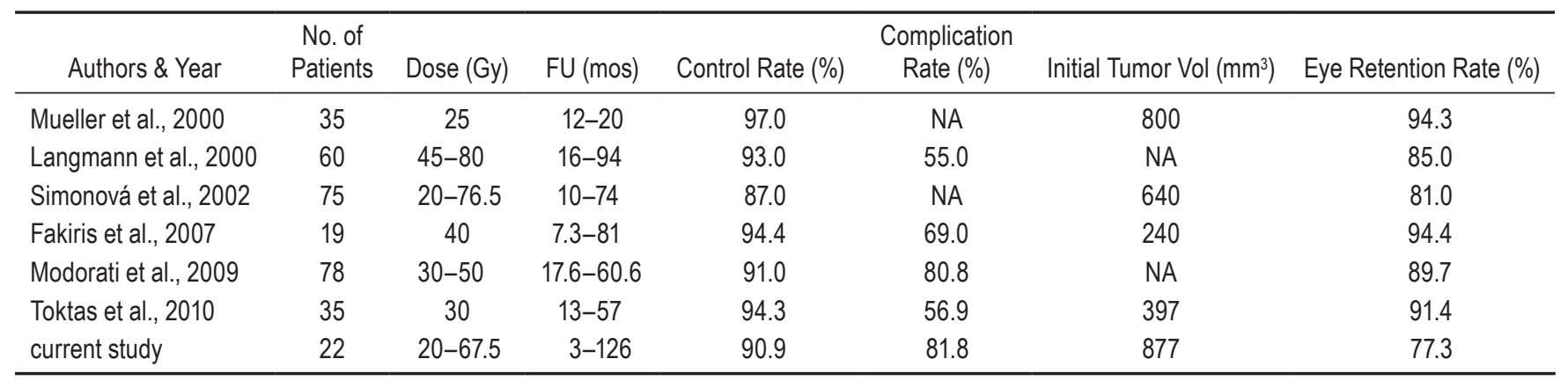

* FU = follow-up; $\mathrm{NA}=$ not available.

ter various treatment methods. ${ }^{2,3,8,27}$ In our study, the rate of enucleation was $22.7 \%$ (5 of 22 patients) at 5-year follow-up after GKS. In 2 patients, the eye globes were enucleated due to tumor recurrence and in 3 others due to subsequent GKS-related complications (severe retinal detachment in 2 patients and neovascularized glaucoma in 1 patient). The eye retention rate was $77.3 \%$ (17 of 22 patients), which is similar to results reported by others..$^{15,18,24}$

\section{Conclusions}

Gamma Knife surgery provided excellent local control of uveal melanomas with remarkable decreases in volume. In our study, a local tumor control rate of $90.9 \%$ and a globe preservation rate of $77.3 \%$ were achieved. The overall minor and major complication rate was $81.8 \%$ (18 of 22 patients), and we observed a higher rate of complications with a higher radiation dose.

Gamma Knife surgery is a safe and minimally invasive method that uses an optimal radiation dose for the treatment of uveal melanomas. This procedure not only preserves the eyeball and its potential visual function, but also decreases the potential for hematological dissemination and achieves sufficient local tumor control with a gradual reduction in volume.

\section{Disclosure}

The authors report no conflict of interest concerning the materials or methods used in this study or the findings specified in this paper.

Author contributions to the study and manuscript preparation include the following. Conception and design: Chang, Park. Acquisition of data: Kang. Analysis and interpretation of data: Chang, Kang, Lee. Drafting the article: Kang. Critically revising the article: Chang. Reviewed submitted version of manuscript: all authors. Approved the final version of the manuscript on behalf of all authors: Chang. Statistical analysis: Kang. Administrative/technical/ material support: Kang.

\section{References}

1. Adams KS, Abramson DH, Ellsworth RM, Haik BG, Bedford $\mathrm{M}$, Packer $\mathrm{S}$, et al: Cobalt plaque versus enucleation for uveal melanoma: comparison of survival rates. Br J Ophthalmol 72:494-497, 1988

2. Castro JR, Char DH, Petti PL, Daftari IK, Quivey JM, Singh $\mathrm{RP}$, et al: 15 years experience with helium ion radiotherapy for uveal melanoma. Int J Radiat Oncol Biol Phys 39:989-996, 1997

3. Char DH, Castro JR, Kroll SM, Irvine AR, Quivey JM, Stone RD: Five-year follow-up of helium ion therapy for uveal melanoma. Arch Ophthalmol 108:209-214, 1990

4. Cohen VM, Carter MJ, Kemeny A, Radatz M, Rennie IG: Metastasis-free survival following treatment for uveal melanoma with either stereotactic radiosurgery or enucleation. Acta Ophthalmol Scand 81:383-388, 2003

5. Damato B: Developments in the management of uveal melanoma. Clin Experiment Ophthalmol 32:639-647, 2004

6. Damato B, Jones AG: Uveal melanoma: resection techniques. Ophthalmol Clin North Am 18:119-128, ix, 2005

7. Dinca EB, Yianni J, Rowe J, Radatz MW, Preotiuc-Pietro D, Rundle P, et al: Survival and complications following Gamma Knife radiosurgery or enucleation for ocular melanoma: a 20year experience. Acta Neurochir (Wien) 154:605-610, 2012

8. Egan KM, Gragoudas ES, Seddon JM, Glynn RJ, Munzenreider JE, Goitein M, et al: The risk of enucleation after proton beam irradiation of uveal melanoma. Ophthalmology 96: 1377-1383, 1989

9. Fakiris AJ, Lo SS, Henderson MA, Witt TC, Worth RM, Danis RP, et al: Gamma-knife-based stereotactic radiosurgery for uveal melanoma. Stereotact Funct Neurosurg 85:106-112, 2007

10. Furdova A, Slezak P, Chorvath M, Waczulikova I, Sramka M, Kralik G: No differences in outcome between radical surgical treatment (enucleation) and stereotactic radiosurgery in patients with posterior uveal melanoma. Neoplasma 57:377381,2010

11. Gambrelle J, Grange JD, Devouassoux Shisheboran M, Rivoire M, Baggetto LG, Jean-Louis B, et al: Survival after primary enucleation for choroidal melanoma: changes induced by the introduction of conservative therapies. Graefes Arch Clin Exp Ophthalmol 245:657-663, 2007

12. Gragoudas ES, Egan KM, Seddon JM, Walsh SM, Munzenrider JE: Intraocular recurrence of uveal melanoma after proton beam irradiation. Ophthalmology 99:760-766, 1992

13. Ikeda H, Jokura H, Yoshimoto T: Transsphenoidal surgery and adjuvant gamma knife treatment for growth hormone-secreting pituitary adenoma. J Neurosurg 95:285-291, 2001

14. Inskip PD, Devesa SS, Fraumeni JF Jr: Trends in the incidence of ocular melanoma in the United States, 1974-1998. Cancer Causes Control 14:251-257, 2003

15. Langmann G, Pendl G, Klaus-Müllner, Papaefthymiou G, Guss H: Gamma knife radiosurgery for uveal melanomas: an 8-year experience. J Neurosurg 93 (Suppl 3):184-188, 2000

16. Marchini G, Gerosa M, Piovan E, Pasoli A, Babighian S, Rigotti M, et al: Gamma Knife stereotactic radiosurgery for uveal melanoma: clinical results after 2 years. Stereotact Funct Neurosurg 66 (Suppl 1):208-213, 1996 
17. Margo CE: The Collaborative Ocular Melanoma Study: an overview. Cancer Contr 11:304-309, 2004

18. Modorati G, Miserocchi E, Galli L, Picozzi P, Rama P: Gamma knife radiosurgery for uveal melanoma: 12 years of experience. Br J Ophthalmol 93:40-44, 2009

19. Mueller AJ, Talies S, Schaller UC, Horstmann G, Wowra B, Kampik A: Stereotactic radiosurgery of large uveal melanomas with the gamma-knife. Ophthalmology 107:1381-1388, 2000

20. Prasad D, Steiner M, Steiner L: Gamma knife surgery for craniopharyngioma. Acta Neurochir (Wien) 134:167-176, 1995

21. Rennie I, Forster D, Kemeny A, Walton L, Kunkler I: The use of single fraction Leksell stereotactic radiosurgery in the treatment of uveal melanoma. Acta Ophthalmol Scand 74: 558-562, 1996

22. Seregard S, aft Trampe E, Lax I, Kock E, Lundell G: Results following episcleral ruthenium plaque radiotherapy for posterior uveal melanoma. The Swedish experience. Acta Ophthalmol Scand 75:11-16, 1997

23. Shields CL, Shields JA, Karlsson U, Menduke H, Brady LW: Enucleation after plaque radiotherapy for posterior uveal melanoma. Histopathologic findings. Ophthalmology 97:16651670,1990

24. Simonová G, Novotný J Jr, Liscák R, Pilbauer J: Leksell gamma knife treatment of uveal melanoma. J Neurosurg 97 (5 Suppl):635-639, 2002

25. Strickland D, Lee JA: Melanomas of eye: stability of rates. Am J Epidemiol 113:700-702, 1981
26. Toktas ZO, Bicer A, Demirci G, Pazarli H, Abacioglu U, Peker $\mathrm{S}$, et al: Gamma knife stereotactic radiosurgery yields good long-term outcomes for low-volume uveal melanomas without intraocular complications. J Clin Neurosci 17:441-445, 2010

27. Wilson MW, Hungerford JL: Comparison of episcleral plaque and proton beam radiation therapy for the treatment of choroidal melanoma. Ophthalmology 106:1579-1587, 1999

28. Woodburn R, Danis R, Timmerman R, Witt T, Ciulla T, Worth $\mathrm{R}$, et al: Preliminary experience in the treatment of choroidal melanoma with gamma knife radiosurgery. J Neurosurg 93 (Suppl 3):177-179, 2000

29. Zehetmayer M, Kitz K, Menapace R, Ertl A, Heinzl H, Ruhswurm I, et al: Local tumor control and morbidity after one to three fractions of stereotactic external beam irradiation for uveal melanoma. Radiother Oncol 55:135-144, 2000

Manuscript submitted May 15, 2012.

Accepted August 1, 2012.

This work was presented at the 16th International Leksell Gamma Knife Society Meeting, Sydney, Australia, March 25-29, 2012.

Please include this information when citing this paper: DOI: 10.3171/2012.8.GKS121002.

Address correspondence to: Jong Hee Chang, M.D., Ph.D., Department of Neurosurgery, Yonsei University College of Medicine, 50 Yonsei-ro, Seodaemun-gu, Seoul 120-752, South Korea. email: changjh@yuhs.ac. 